\title{
Monitoring and Testing Different Doses of Disparlure for Indian Gypsy Moth, Lymantria obfuscata, in a Temperate Region of India (Kashmir Valley)
}

\author{
B. HUSSAIN, ${ }^{1 *}$ A. R. WAR, ${ }^{2}$ S. A. GANIE ${ }^{1}$ and S. BILAL ${ }^{1}$ \\ 'Division of Entomology, SKUAST-Kashmir, Shalimar Campus, Shalimar, Srinagar, India \\ ${ }^{2}$ ICRISAT, Patencheru, Hyderabad, AP, India
}

(Received: 15 June 2014; accepted: 9 July 2014)

\begin{abstract}
Pheromone traps with different doses of disparlure [(Z)-7,8-epoxy-2-methyloctadecane] were tested for a local strain of the Indian gypsy moth (Lymantria obfuscata) at Sher-e-Kashmir University of Agricultural Sciences and Technology of Kashmir (India). Disparlure at $500 \mu \mathrm{g}$ dose proved to be effective in trapping gypsy moth populations. The first adults were caught on the third week of June in 2007-2009 with peak catches a week later. Catches in disparlure-baited traps at all dosage levels $(0.5,50$ and $500 \mu \mathrm{g})$ were significantly higher as compared to control traps. The regression equation revealed strong (99\%) correlation between moth catches and applied doses. The accumulated degree day model predicted 65.31 to 117.97 heat units for larval hatch and 794.66 to 928.15 heat units for adult emergence. The principal component analysis showed significant variability between weather variables and adult $L$. obfuscata population.
\end{abstract}

Keywords: pheromone, dosage, Lymantria obfuscata, monitoring, forecasting.

The Indian gypsy moth, Lymantria obfuscata Walker (Lepidoptera: Lymantriidae), is an important pest of forest and fruit trees in Kashmir Valley in India (Beeson, 1941), and is prevalent in mountain and sub-mountain regions of the northwestern Himalayas and in the rest of the country. Caterpillars are voracious nocturnal foliage feeders, which, during the day, aggregate in large numbers on the ground under fallen leaves or on the lower parts of well-shaded branches. Tender leaves are preferred by the larvae. Adult males fly actively, while females are wingless. Lymantria spp. are polyphagous, damaging plantations of Alnus nitida Mill: Betulaceae; Cydonia vulgaris Mill: Rosaceae; Juglans regia L: Juglandaceae; Populus spp L: Salicaceae; Pyrus malus L: Rosaceae; Quercus dilatata L: Fagaceae; Robinia pseudoacacia L: Fabaceae; Salix alba L: Salicaceae; S. babylonica L: Salicaceae; and S. fragilis L: Salicaceae (Roonwal, 1953; Zutshi, 1967).

Pheromone-baited traps are effective tools in integrated pest management, because they are easy to operate, species-specific, and effective at low population densities (Munshi et al., 2008). They can be used, in combination with other methods, to provide estimates of population densities and to monitor populations for the implementation of envi-

* Corresponding author; e-mail: bhatbari@ rediffmail.com

0238-1249/\$20.00 (C) 2015 Akadémiai Kiadó, Budapest 
ronmentally sound management strategies (Sanders, 1988), with examples including insect pests of forest (Granett, 1974; Shepherd et al., 1985; Evenden, 2005) and agricultural ecosystems (Shelton and Wyman, 1979; Tingle and Mitchell, 1981; Ngollo et al., 2000). Also, disruption of chemical communication between the sexes can also be an option for control (Hussain et al., 2014)

Studies have been conducted on the use of disparlure [(Z)-7,8-epoxy-2-methyloctadecane], sex pheromone of $L$. dispar L., for monitoring population dynamics (Schwalbe and Mastro, 1988; Webb et al., 1988), but no such reports are available for L. obfuscata, which is considered to be one of the most destructive defoliators of hardwood trees in Kashmir. Furthermore, the degree day model for different developmental stages of $L$. obfuscata is still not available. This study was aimed: (i) to evaluate the optimal pheromone dose for trapping males; and (ii) to develop a degree day model to establish the heat units required from one developmental stage to another. Also, trap catch data of L. obfuscata from 2007-2009 were correlated with weather variables to create a platform for forecasting population trends of L. obfuscata in India and in Kashmir Valley.

\section{Materials and Methods}

Study area

Studies were carried out in newly established apple tree blocks of Red Delicious variety planted with pollinizers such as Golden Delicious, Gala mast and Red Gold, aged between 10-15 years, at Sher-e-Kashmir University of Agricultural Sciences and Technology of Kashmir (SKUAST-K) Shalimar, Srinagar, India.

\section{Field trials of different doses of disparlure}

Disparlure and delta traps with sticky sheets to capture moths were supplied by Horticulture Research International, New Zealand, free of cost, as no company in India is manufacturing gypsy moth lures. Traps baited with $0.5,50$ and $500 \mu \mathrm{g}$ amounts of disparlure on rubber septa, and those baited with hexane (control), were hung 1.5 meter above the ground on apple trees, with ten meters between treatments. Each treatment was repeated five times. Traps were installed on $10^{\text {th }}$ of June each year and gypsy moth males caught were recorded on a weekly basis until the end of the flight season.

\section{Monitoring the population dynamics of $\mathrm{L}$. obfuscata}

Delta traps baited with $500 \mu \mathrm{g}$ disparlure were used for monitoring the population dynamics of adult male L. obfuscata in an apple orchard block at SKUAST-K, Srinagar, India. Twenty delta traps were installed in a 20-year old apple orchard of Red Delicious variety during 2007-2009, and the population dynamics of L. obfuscata were studied throughout the whole season. 
Seasonal activity of $\mathrm{L}$. obfuscata

The life cycle of L. obfuscata was studied in the laboratory at the Division of Entomology, SKUAST-K, during 2008-2010. Fully grown caterpillars were collected from abandoned orchards, and were reared in wooden cages $(30 \times 30 \times 30 \mathrm{~cm})$ at room temperature. Fresh leaves of Salix spp. served as food for the larvae, and were provided daily. A $5 \mathrm{~cm}$ thick layer of dry soil was put at the bottom of the cages to aid pupation. Pupae were transferred daily into another cage for adult emergence. Newly emerged moths were released in pairs in wooden cages for egg-laying, and cotton swabs soaked in 10 per cent sucrose solution were provided as food to adults. The eggs laid by each female on the walls of the rearing cages were removed daily with the help of a moist camel hair brush.

\section{Degree day model for $\mathrm{L}$. obfuscata}

A degree day model for L. obfuscata was developed during a two-year period for egg, larvae, pupae and adults. Degree-days (oD) is a measurement unit to determine the heat units necessary for development in order to forecast pest outbreaks (Arnold, 1960). Degree days (often referred as "growing degree days") are accurate because insects have a predictable development pattern based on heat accumulation. The weather data used for the degree day modeling of L. obfuscata was taken from a mini-weather station at Shalimar Campus.

Degree days were calculated by the following method:

$$
\begin{array}{ll}
\mathrm{oD} & =[(\mathrm{Tmax}+\mathrm{Tmin}) / 2]-\mathrm{TL} . \\
\text { Where: } \mathrm{TL} & =\text { Threshold Temperature }\left(10^{\circ} \mathrm{C}\right), \\
\text { Tmax } & =\text { Maximum temperature for the particular day, } \\
\text { Tmin } & =\text { Minimum temperature for the particular day. }
\end{array}
$$

\section{Data analysis}

Trapping data at different doses of disparlure were statistically analyzed by the best power fit line using computer assisted Statistical Software SPSS (15.1), and by analysis of variance (ANOVA). Cumulative trapping data, maximum and minimum temperature and maximum and minimum relative humidity were evaluated by principal component analysis.

\section{Results and Discussion}

\section{Field trials with different doses of disparlure}

When testing different doses $(0.5,50$ and $500 \mu \mathrm{g})$ of disparlure, lowest catches were recorded at $0.5 \mu \mathrm{g}$ dose, and highest at $500 \mu \mathrm{g}(P=0.05$, ANOVA). Dose response curve (Fig. 1) was calculated by regression equation as $\mathrm{Y}=10.41 \mathrm{x}-10.2$, with a regression coefficient $\left(\mathrm{R}^{2}=0.9959\right)$ of $99 \%$, revealing strong correlation between applied doses 


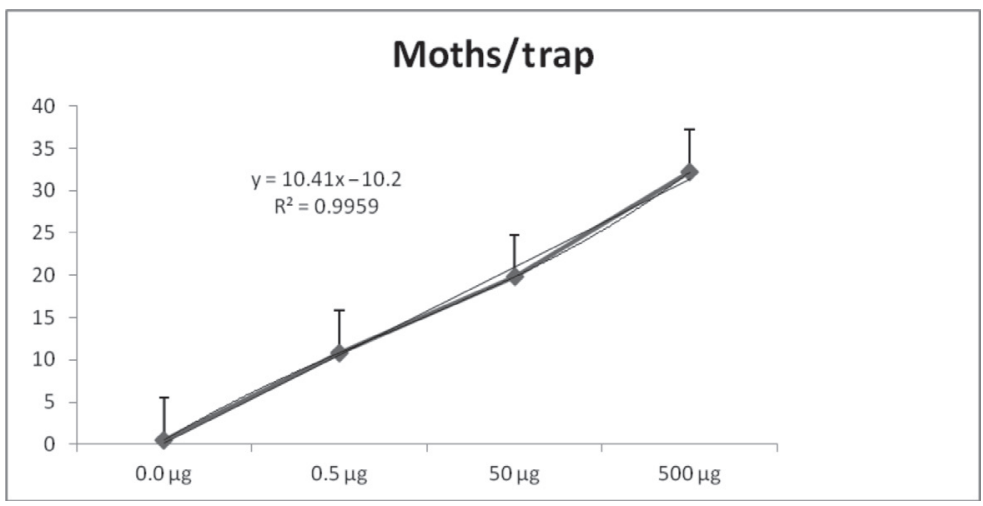

Fig. 1. Linear regression trend line for male L. obfuscata at various dosage levels of disparlure in Kashmir Valley

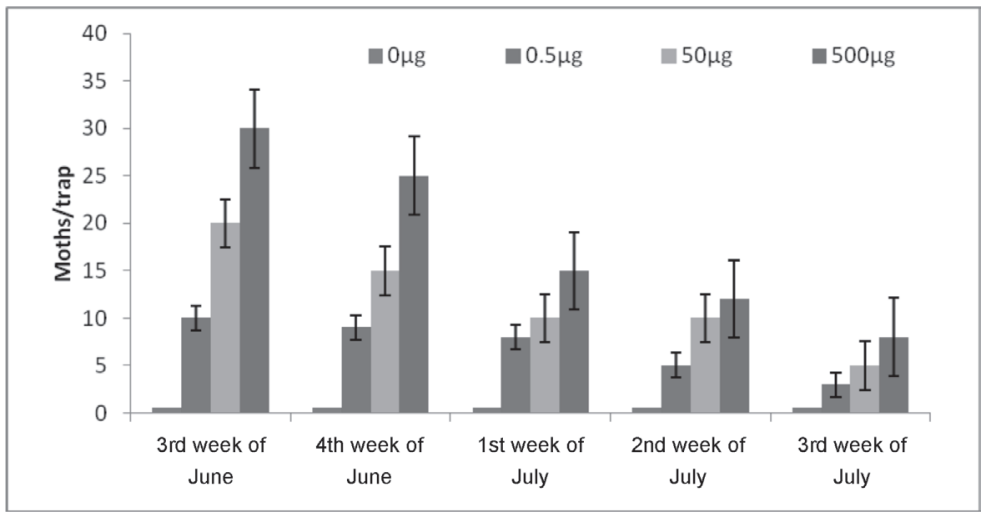

Fig. 2. Monitoring the population of adult male L. obfuscata at different dosage levels in Kashmir Valley

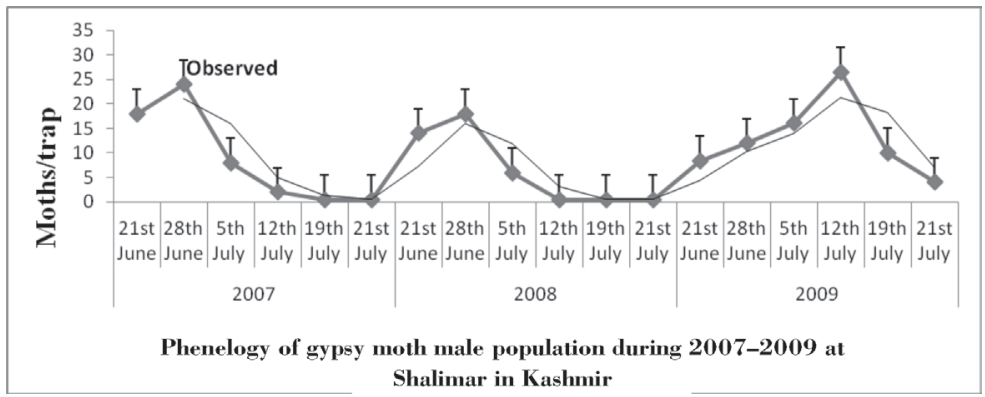

Fig 3. Monitoring the population of $L$. obfuscata, using $500 \mu \mathrm{g}$ disparlure, from appearance to disappearance in Kashmir valley 
and trap catches. Trapping at high population densities of $L$. dispar (Thorpe et al., 1999) showed decrease in moth capture with increasing doses of disparlure (Schwalbe and Mastro, 1988; Webb et al., 1988), but the results of the present investigation may suggest that the highest dosage is effective even at low population densities of L. obfuscata. Sex pheromone lures have been used to study the behavioral polymorphism of L. dispar (Beroza et al., 1973; Punjabi et al., 1974), but no such studies have yet been undertaken for L. obfuscata. In general, trap catches are likely to vary depending on the parameters of the trap design, height of the lures and ratio of the components of the lure and environmental conditions (Thorpe et al., 1999).

\section{Monitoring the population dynamics of $\mathrm{L}$. obfuscata}

Monitoring the population dynamics of L. obfuscata during 2007-2009, using $500 \mu \mathrm{g}$ disparlure/trap, revealed first catches of L. obfuscata in the $3^{\text {rd }}$ week of June, and peak catches from mid June to mid July, declining after the $2^{\text {nd }}$ week of July (Fig. 2). $L$. obfuscata catches during 2007 and 2008 were highest between the $3^{\text {rd }}$ and $4^{\text {th }}$ weeks of June. However, in 2009, highest catches were recorded between the $1^{\text {st }}$ and $2^{\text {nd }}$ weeks of July, and catches were still recorded up until the $4^{\text {th }}$ week of the month. During the years 2007-2009 as depicted in Fig. 3, highest catches were observed on the $4^{\text {th }}$ week of June. Simple trend line of the three years data showed variability in trap catches (Fig. 3), which could be attributed to fluctuation of weather factors.

Disparlure-baited traps are therefore suggested to be utilized in monitoring and surveillance programs in the Kashmir valley against L. obfuscata. Trapping and phenology of L. obfuscata males could be exploited to determine the approximate timing of control strategies against this pest.

\section{Seasonal activity of $\mathrm{L}$. obfuscata}

L. obfuscata overwinters in egg stage, followed by larval hatch from the last week of March until the end of the month. Newly hatched larvae are small and buff-coloured, but turn black within a few hours. The latter instars are hairy and blackish, with several light orange dots on the last half of the back. Total larval period lasts for 66 days (Table 1). The pupae are mahogany-coloured, and pupation lasts for about 4-12 days. Females are

Table 1

Seasonal activity and appearance of different phenological stages of L. obfuscata in Kashmir valley

\begin{tabular}{lccccl}
\hline \multicolumn{1}{c}{ Stages } & Minimum days & Maximum days & Range & Mean \pm S.E. & Period of activity \\
\hline Egg & 242 & 270 & $242-270$ & $260 \pm 0.04$ & Mid June to last week of March \\
Larval & 50 & 66 & $50-60$ & $57 \pm 050$ & Last week of March to end of May \\
Pupal & 4 & 12 & $4-12$ & $9 \pm 0.30$ & First week of June to mid June \\
Adult & 3 & 30 & $3-30$ & $26 \pm 0.70$ & Mid June to mid July \\
\hline
\end{tabular}




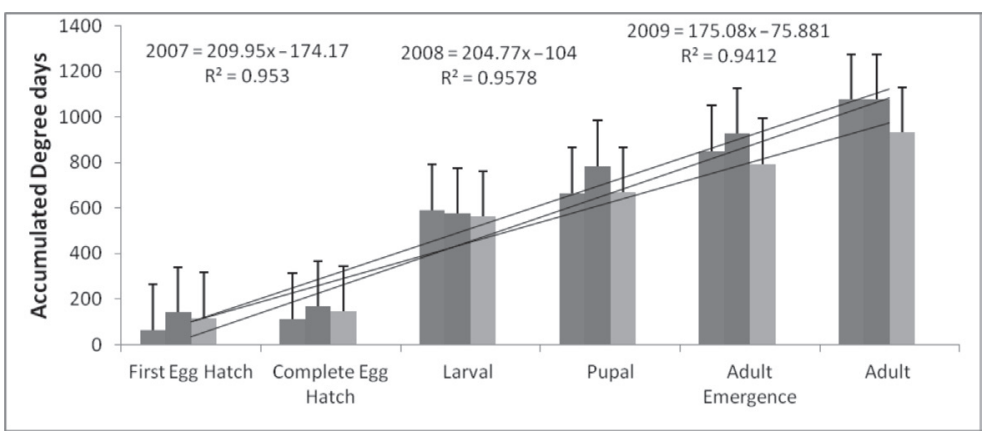

Fig 4. Degree day model for L. obfuscata at different phenological stages accumulated at each stage during 2007-2009

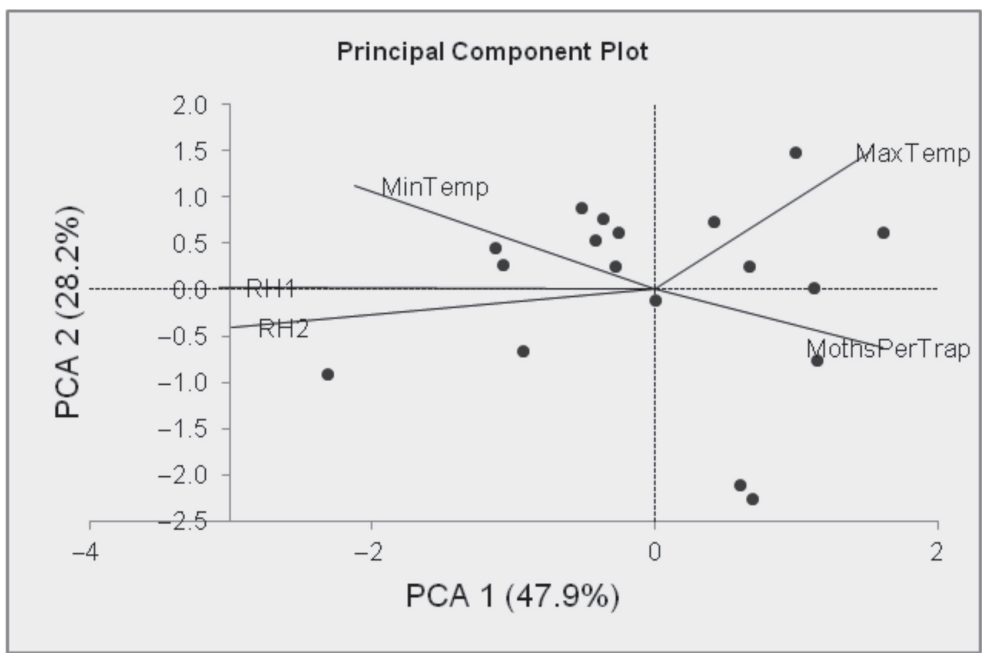

Fig 5. Principal component analysis of trap catch data of L. obfuscata and different climatic variables

wingless, unable to walk and white in colour. Males are smaller, dark brown with blackish markings and are strong fliers, being active from mid June to mid July.

\section{Degree day model for L. obfuscata}

Cumulative degree day model at different phenological stages of L. obfuscata revealed egg hatch between 65.31 to 117.97 heat units. Larvae accumulated 562.66 to 592.55 heat units, whereas adults 794.66 to 928.15 heat units. To acquire the exact number of heat units required from egg to adult stage is based on cumulative degree days to forecast different phenological stages of L. obfuscata, which could be used as biofix (a biological event or indicator of a developmental event, usually in the life of an insect pest, that initiates the beginning of growing-degree-day calculations) in the degree day model for egg hatch. 
On the other hand, accumulated degree days varied between 2007 and 2009 and could be attributed to weather and other factors prevailing during the spring season (Andresen et al., 2001). Degree day models may be potential tools for the management of L. obfuscata populations. Management strategies are thus predicted to be applied at about 562.66 to 592.51 degree days for the larvae. Regression model developed between 2007 and 2009 (Fig. 4) revealed strong regression coefficient of $\mathrm{R}^{2}=0.94 \%$ as compared to 2007 and 2008. Larval emergence between 562.66-592.55 degree days should therefore be viewed with caution. Also, first instar larvae can be transferred by the wind from infested to non-infested areas. Adult average degree days of 857.33 can be a sign of starting monitoring (Arnold, 1960). Principal component analysis revealed (Fig. 5) that maximum temperature showed more variability as compared to other variables for L. obfuscata populations.

\section{Acknowledgement}

Authors are thankful to Ashraf-al-Sayeed, Horticulture Research International, New Zealand for providing lures and traps free of cost and his valuable suggestions during the period of experimentation.

\section{Literature}

Andresen, J. A., Mccullough, D. G., Potter, B. E., Koller, C. N., Bauer, L. S., Lusch, D. P. and Ramm, C. W. (2001): Effects of winter temperatures on gypsy moth egg masses in the Great Lakes region of the United States. Agriculture for Meteorology 110, 85-100.

Arnold, C. Y. (1960): Maximum - minimum temperatures as a basis for computing heat units. American Society for Horticultural Sciences76, 682-692.

Beeson, C. F. C. (1941): The Ecology and Control of the Forest Insects of India and the Neighboring Countries. Vasant Press, Dehradun, pp. 1-767.

Beroza, M., Punjabi, A. A. and Bierl, B. A. (1973): Disparlure and analogues as attractants for Lymantria obfuscata. J. Econ. Entomol. 66, 1215 p.

Evenden, M. L. (2005): Potential for combining sex pheromones for the forest tent caterpillar (Lepidoptera: Lasiocampidae) and the large aspen tortrix (Lepidoptera: Tortricidae) within monitoring traps targeting both species. Canadian Entomologist 137, 615-619.

Granett, J. (1974): Estimation of male mating potential of gypsy moths with disparlure baited traps. Environ. Entomol. 3, 383-385.

Hussain, B., Ahmad, B. and Sheikh, B. (2014): Monitoring and mass trapping of codling moth, Cydia pomonella by the use of pheromone baited traps in Kargil, Ladakh, India. Int. J. of Fruit Sciences, DOI:10.1080/15 538362.2013.819207.

Munshi, N. A., Hussain, B., Malik, G. N., Yousuf, M. and Fatima, N. (2008): Efficacy of entomopathogenic fungus, Fusarium palidoroseum (Cooke) Sacc. against gypsy moth Lymantria obfuscata Walker. J. Entomol. 5, 59-61.

Ngollo, E. D., Groden, E., Dill, J. F. and Handley, D. T. (2000): Monitoring of the European corn borer (Lepidoptera:Crambidae) in central Maine. J. Econ. Entomol. 93, 256-263.

Punjabi, A. A., Berroza, M. and Bierl, B. A. (1974): Trapping of Lymantria obfuscata Walker with disparlure. Indian J. Entomol. 36, 125-127.

Roonwal, M. L. (1953): Unusual population eruption of the moth, Lymantria mathura Moore in autumn. Current Sci. 22, 384 p.

Sanders, C. J. (1988): Monitoring spruce budworm population density with sex pheromone traps. Canadian Entomol. 120, 175-183. 
Schwalbe, C. P. and Mastro, V. C. (1988): Gypsy moth mating disruption: dose effects. J. Chemical Ecol. 14, 581-588.

Shelton, A. M. and Wyman, J. A. (1979): Time of tuber infestation and relationships between pheromone catches of adult moths, foliar larval populations and tuber damage by the potato tuberworm (Lepidoptera: Gelechiidae). J. Econ. Entomol. 72, 599-601.

Shepherd, R. F., Gray, T. G., Chorney, R. J. and Daterman, G. E. (1985): Pest management of Douglas-fir tussock moth, Orgyia pseudotsugata (Lepidoptera: Lymantriidae): monitoring endemic populations with pheromone traps to detect incipient outbreaks. Canadian Entomol. 117, 839-848.

Thorpe, K. W., Mastro, V. C., Leonard, D. S., Leonhardt, B. A., McLane, W., Reardon, R. C. and Talley, S. E. (1999): Comparative efficacy of two controlled-release gypsy moth mating disruption formulations. Entomologia Experimentalis et Applicata 90, 267-277.

Tingle, F. C. and Mitchell, E. R. (1981): Relationships between pheromone trap catches of male tobacco budworm, larval infestations, and damage levels in tobacco. J. Econ. Entomol. 74, 437-440.

Webb, R. E., Tatman, K. M., Leonhardt, B. A., Plimmer, J. R., Boyd, V. K., Bystrak, P. G., Schwalbe, C. P. and Douglass, L. W. (1988): Effect of aerial application of racemic disparlure on male trap catch and female mating success of gypsy moth (Lepidoptera: Lymantriidae). J. Econ. Entomol. 81, 268-273.

Zutshi, M. K. (1967): Lymantria obfuscata Walker and its natural enemies in Kashmir. J. of Bombay Natural History Society 64, 126-129. 